\title{
Prevalence of Malocclusion and Orthodontic Treatment Needs in Down Sundrome Sudanese Individuals
}

\author{
Dr Hiba A. Ibrahim,' Dr Amal H. Abuaffan² \\ 'General Dentist, ${ }^{2}$ Assoc Professor, Dept of Orthodontics, University of Medical Science \& Technology
}

Khartoum, Sudan

Correspondence: Dr Hiba A. Ibrahim; email: hibaamirg1@gmail.com

\section{ABSTRACT}

Objective: To determine prevalence of malocclusion and orthodontic treatment needs in Down syndrome individuals among Sudanese population in Khartoum area.

Materials \& Method: A total of 75 (37 males and 38 females) Down syndrome individuals age ranging from 6-28 years were clinically examined after obtaining their guardian's consent, malocclusion was determined based on Angle and Incisor classification. Exclusion criteria were included individuals who had history of extraction and orthodontic treatment.

Data was analysed by using SPSS Version 17, at an alpha level 0.05 and $95 \%$ confidence limits.

Result: Angle Class III and Incisor III malocclusion represents the most prevalent type of malocclusions (58.7\%) Angle classification, (53.3\%) Incisors classification. Angle Class III malocclusion was more frequent among females (60.5\%) than in males (56.8\%). The majority of individuals with Down syndrome are in need of orthodontic treatment (85.3\%).

Conclusion: The prevalence of malocclusion and orthodontic treatment need among Sudanese Down syndrome individuals was high. Angle and Incisor Class III malocclusion representing commonest trait of malocclusion with more frequency in females than males.

Key word: down syndrome, Class III malocclusion, orthodontic treatment

\section{INTRODUCTION}

Down syndrome (DS) is a genetic condition caused by the presence of an extra chromosome 21, or sometimes caused by the duplication of small regions of the chromosome. This condition affects 1 in 800-1100 births, Down syndrome is a major cause of mental retardation and congenital heart disease. It also causes distinct facial and physical features, Down syndrome is associated with congenital anomalies of the gastrointestinal tract, an increased risk of leukaemia, immune system defects, and an Alzheimer-like dementia.

Down syndrome was first described in 1866 by Dr John L. H. Down, Down syndrome patients have many dental conditions suited to be considered for orthodontic treatment. ${ }^{2}$

Down syndrome individuals possess some unique characteristics: systemic anomalies which include arterial septal defects, patent ductus arteriosus, lymphopenia, eosinopenia, Leukemia, increased laxity of ligaments, underdeveloped mid face, delayed motor function, dementia, natural spontaneity, genuine warmth, gentleness, patience, tolerance, ventricular septal defect, and few patients present with anxiety and stubbornness. Oral anomalies include; reduction in length height and depth of the palate, hypotonic tongue, fissured tongue, scalloped tongue, and macroglossia. ${ }^{3}$

Dental anomalies include delayed eruption of primary teeth to a year or more instead of around six month, delayed eruption of permanent teeth, reduction in size of teeth, presence of spacing due to small sized teeth, missing teeth, malpositioned teeth, microdontia hypolplasia partial anodontia, supernumerary teeth, hypodontia spacing, taurodontism, crown variants, difference in the order of teeth eruption, deficient growth in the upper arch and bruxism. ${ }^{3-4}$

Occlusion is defined as the manner in which the upper and lower teeth intercuspate between each other in all mandibular positions and movements. It is a result of neuromuscular control of the components of the masticatorry system namely: teeth, periodontal structures, maxilla, mandible, temporomandibular joints and their associated muscles and ligaments. ${ }^{5}$ 
Malocclusion term was first invented by Guilford, it occurs in the majority of the population. It is neither a normal or unhealthy condition. It is difficult to prove a single major cause of malocclusion as it develops slowly as a child grows and the development of occlusion is very vulnerable to many influences. ${ }^{6}$

Malocclusion is defined as an anomaly which causes disfigurement or which impedes function, and require treatment, if the disfigurement or functional defect was likely to be an obstacle to the patient's physical or emotional wellbeing. Malocclusion might be associated with one or more of the following: malalignment of individual teeth in each arch, malrelationship of the dental arches relative to the normal occlusion; (In anteroposterior, vertical or transverse planes). ${ }^{5}$

In the twenty first century, researches proposed two broad set of theories to explain causes of occlusal variation; genetics and the role of environment. $6,7,8$

Proffit ${ }^{6}$ and McDonald ${ }^{8}$ had suggested that crowding and malalignment are primarily due to inherited tendencies that determine facial proportions and soft tissue contour, as well as teeth and jaw size. Mild and moderate degree of malalignment might be present even in the absence of habits or environmental factors, however extremely severe crowding probably has genetic component as well as environmental component.

\section{Classification of malocclusion}

Different methods of classification of malocclusion are needed for different purposes. The requirements for clinical categorization differ from those of epidemiology.?

Several types of indices has been developed to describe the malocclusion; epidemiological data collection (which measure the occlusal traits), 10 occlusal classification (Angle's classification)," priority treatment need - dental health need, ${ }^{12}$ Index of Orthodontic Treatment need, ${ }^{13}$ Treatment success (which compares pre and post orthodontic treatment records and register the quality of the outcome) ${ }^{14}$ and the Dental arch relationships (Which categorizes dental arch relationships in children with unilateral complete cleft lip and palate)..$^{15}$

The need of treatment depends on the aesthetics and if treatment is detrimental to heath of the teeth and the supporting structures. ${ }^{16}$

According to a statistical study done by US Census Bureau to determine the incidence of Down syndrome around the world; in Sudan out of 39148162 individual examined, 48935 were found to have down syndrome. ${ }^{17}$
In spite of this high number, no published studies regarding the malocclusion and need for orthodontic treatment among individuals with Down syndrome was available. Therefore this study was designed to determine the prevalence of malocclusion and orthodontic treatment need in a sample of Down syndrome individuals in Khartoum area.

\section{MATERIALS AND METHOD}

All the special needs centers in Khartoum area were located. Preliminary visit to the centers to explain the purpose of the study, and to obtain permission from the head of the centers and parents to carry on this study, then a cross-sectional descriptive community-based study was carried out on Dawn syndrome individuals.

All Down syndrome individuals whose parent agreed to participate in the study and sign the consent paper were included in this study. The clinical examination was carried out in the teachers' office sitting on chair in front of the investigator using natural day light, sterilized examination sets were used for each individual, and data sheet was filled for each. Individuals who had dental problems malocclusion or bad oral hygiene were referred to the dental clinic at the University of Medical Science and Technology for the required treatment.

The sample included all individuals' with Down syndrome attending special need centers, except for the ones who received or were receiving orthodontic treatment.

The following criteria were used to assess the type of malocclusion. ${ }^{18}$

\section{Angle classification of malocclusion}

Class I: Normal relationship of the molars, but line of occlusion incorrect Due to malposed teeth, rotations, or other causes.

Class II: Lower molar distally positioned relative to upper molar.

Class III: Lower molar mesially positioned relative to upper molar.

\section{Incisor classification of malocclusion}

Class I: The lower incisor edges lies below the cingulum plateau of upper central incisors.

Class II: The lower incisors edges lies posterior to the cingulum plateau of upper central incisors:

Division 1: Proclined upper incisors and increased over jet.

Division 2: Retroclined upper incisors and decreased over jet. 
Class III: The lower incisors edge lies anterior to the cingulum plateau of the upper incisors, over jet reduced or reversed.

\section{Data management and analysis:}

Data was analysed by a specialized statistician using Statistical Package for Social Sciences (SPSS) Version 17, at an alpha level 0.05 and $95 \%$ confidence limits.

\section{RESULT}

The total number of Down syndrome individuals in the special need centre in Khartoum area was 98, three individual had orthodontic treatment and 20 individual parents refused to retain the consent form. Therefore, the number included the present study was 75 Individuals; 37 (49.3\%) males, and 38 $(50.7 \%)$ females. The age range of the examined group was 6-23 years old. Table 1 shows that, the most prevalent type of malocclusion according to Angle's classification was Class III malocclusion found in all age groups followed by Class II, even though no significant association was found between Angle's classification of malocclusion and age group. Table 2 shows that Angle Class III malocclusion was the most frequent type of malocclusion representing in females (60.5\%), compared to males (56.8\%), even though no significant association was found. Table 3 shows that Incisor Class III malocclusion was the highest type (58.1\%) among all age groups flowed by Class II but no significant association was found. Table 4 shows that Incisor Class III was the most frequent among both genders, $54.1 \%$ in males, $52.6 \%$ in females, followed by Class I and Class II malocclusion but no significant association was found.

Figure 1 shows that the vertical malocclusion in examined Down syndrome individuals; open bite was found to be $38.7 \%$ followed by edge to edge bite in $32.0 \%$ and only $8 \%$ had normal bite. Figure 2 show frequency of individuals that require treatment in each age group. Figure 3 shows out of 37 examined males 32 need treatment, and out of examined 38 females also 32 need treatment.

Table 1: Distribution of Angle classification in the different age groups

\begin{tabular}{|c|c|c|c|c|}
\hline \multirow{2}{*}{ Angle classification } & \multicolumn{3}{|c|}{ Age group } & \multirow{2}{*}{ Total } \\
\cline { 2 - 4 } & $6-11$ years & $12-17$ years & $\mathbf{1 8 - 2 3}$ years & $9(12.0 \%)$ \\
\hline Class I & $2(6.5 \%)$ & $6(20.0 \%)$ & $1(7.1 \%)$ & $22(29.3 \%)$ \\
\hline Class II & $10(32.3 \%)$ & $6(20.0 \%)$ & $6(42.9 \%)$ & $44(58.7 \%)$ \\
\hline Class III & $19(61.3 \%)$ & $18(60.0 \%)$ & $7(50.0 \%)$ & $75(100 \%)$ \\
\hline Total & $31(100 \%)$ & $30(100 \%)$ & $14(100 \%)$ & 7 \\
\hline
\end{tabular}

Table 2: Distribution of Angle classification among gender groups

\begin{tabular}{|c|c|c|c|}
\hline \multirow{2}{*}{ Angle classification } & \multicolumn{2}{|c|}{ Gender } & \multirow{2}{*}{ Total } \\
\cline { 2 - 4 } & Male & Female & $9(12.0 \%)$ \\
\hline Class I & $6(16.2 \%)$ & $3(7.9 \%)$ & $22(29.3 \%)$ \\
\hline Class II & $10(27.0 \%)$ & $12(31.6 \%)$ & $44(58.7 \%)$ \\
\hline Class III & $21(56.8 \%)$ & $23(60.5 \%)$ & $75(100 \%)$ \\
\hline Total & $37(100 \%)$ & $38(100 \%)$ & 7 \\
\hline
\end{tabular}

Table 3: Incisor classification in different age groups

\begin{tabular}{|c|c|c|c|c|}
\hline \multirow{2}{*}{ Incisor classification } & \multicolumn{3}{|c|}{ Age group } & Total \\
\cline { 2 - 5 } & $\mathbf{6}-11$ years & $\mathbf{1 2}-\mathbf{1 7}$ years & $\mathbf{1 8 - 2 3}$ years & $12(16.0 \%)$ \\
\hline Class I & $2(6.5 \%)$ & $9(30.0 \%)$ & $1(7.1 \%)$ & $23(30.7 \%)$ \\
\hline Class II & $11(35.5 \%)$ & $6(20.0 \%)$ & $6(42.9 \%)$ & $40(53.3 \%)$ \\
\hline Class III & $18(58.1 \%)$ & $15(50.0 \%)$ & $7(50.0 \%)$ & $75(100 \%)$ \\
\hline Total & $31(100 \%)$ & $30(100 \%)$ & $14(100 \%)$ & 7 \\
\hline
\end{tabular}


Table 4: Incisor classification among gender groups

\begin{tabular}{|c|c|c|c|}
\hline \multirow{2}{*}{ Incisor classification } & \multicolumn{2}{|c|}{ Gender } & \multirow{2}{*}{ Total } \\
\cline { 2 - 4 } & Male & Female & $12(16.0 \%)$ \\
\hline Class I & $7(18.9 \%)$ & $5(13.2 \%)$ & $23(30.7 \%)$ \\
\hline Class II & $10(27.0 \%)$ & $13(34.2 \%)$ & $40(53.3 \%)$ \\
\hline Class III & $20(54.1 \%)$ & $20(52.6 \%)$ & $75(100 \%)$ \\
\hline Total & $37(100 \%)$ & $38(100 \%)$ & $700 \%$ \\
\hline
\end{tabular}

Figure 1: Vertical malocclusion among Down syndrome individuals.

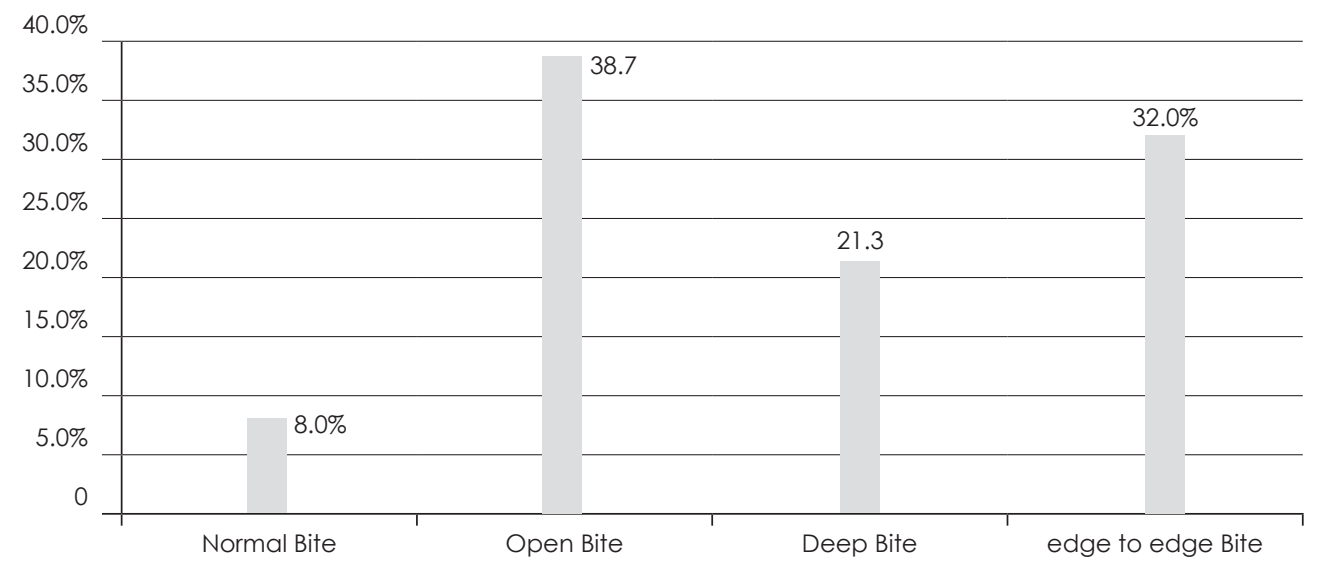

Figure 2: Distribution of orthodontic treatment need in different age group with Down syndrome

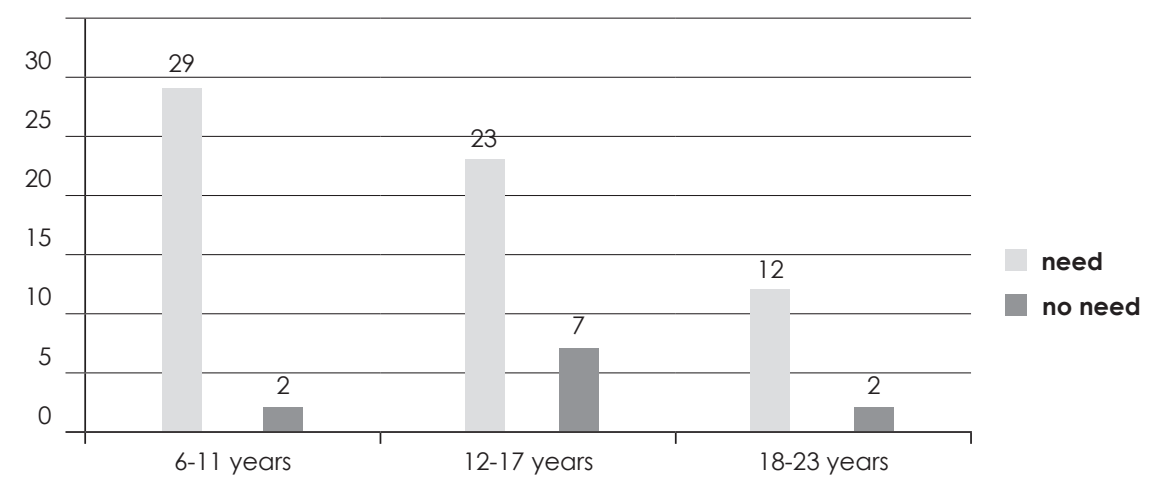

Figure 3: Orthodontic treatment need for Down syndrome individual in both genders.

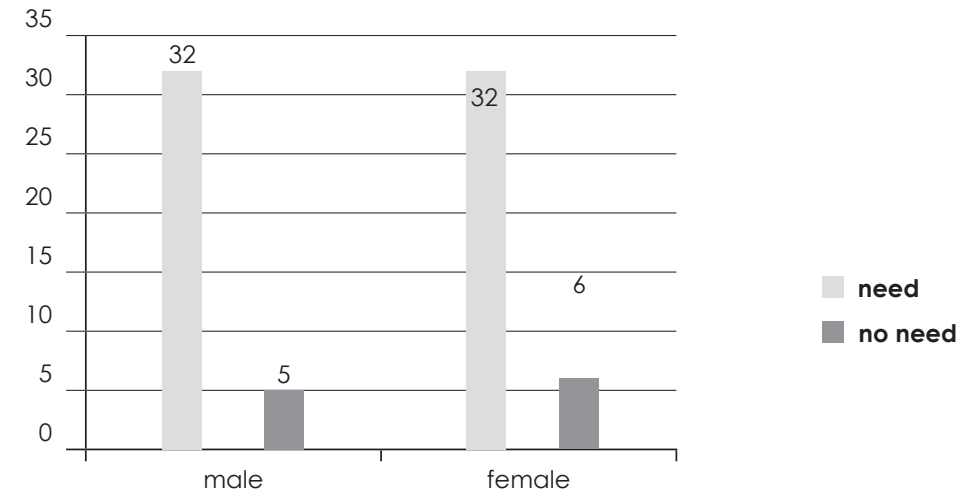




\section{DISCUSSION}

The aim of this study was to determine the prevalence of malocclusion and orthodontic treatment need in Down syndrome individuals attending special needs centres in Khartoum area.

The small number of Down syndrome in the special need institutions may be partially attributed to the lack of Knowledge about the syndrome itself among the population and the majority of parents prefer the child stay at home for safety and better care than out door.

The present study showed that the predominant Angle classification among Down syndrome individuals was Class III malocclusion (58.7\%) and the percent of open bite was (38.7\%), which in consistent to the studies carried out by Folakemi and Yinka. In Nigeria and Croatia population in which Angle Class III malocclusion was reported (60\%), and (43.8\%) respectively and open bit percent was (8\%)..$^{19,20}$ However Very high percentage (70\%) of Class III malocclusion was reported in Saudi Arabia. ${ }^{21}$

The percent of Class III malocclusion among normal Sudanese population was very small (3\%). ${ }^{22}$ The fact that Class III malocclusion is predominate feature among Down Syndrome population.

In the current studies, the prevalence of malocclusion was noted to be very high (85.3\%). A little less percentage (74\%) was reported in Rio de Janeiro, ${ }^{23}$ and in Amman Jordan was $45.3 \% .^{24}$ In Nigeria, Onyeaso reported that only $17 \%$ of Down syndrome individuals had definite malocclusions with treatment elective, $9 \%$ had severe malocclusions and treatment highly desirable and $32 \%$ had very severe or handicapping malocclusions with treatment considered mandatory. ${ }^{25}$ Moreover in South Canara, India a low percentage $(24 \%)$ of orthodontic treatment need was reported. ${ }^{26}$

The differences in results between Down and normal individuals in all malocclusion classifications may be due to the known skeletal conditions among Down syndrome individuals, while difference in results between down syndrome individuals in different countries may be partially attributed to the difference in age groups, gender, geographical area, environmental factors and ethnic background.

\section{CONCLUSION}

High prevalence of malocclusion and orthodontic treatment need was seen among the sample of Sudanese Down syndrome individuals. Angle and incisor Class III malocclusion representing commonest trait, with more frequency in females than males. Comprehensive investigation should be carried out to include different areas in Sudan in order to know the overall prevalence of Down syndrome individuals, as well as malocclusion and treatment need. Health service centers should have special attention to those handicapped population, and should establish educational programs about dental awareness and oral hygiene information for parents and teachers in special needs centers, so that those group of individual with Down syndrome can get more attention. Mental and or physical limitations should not be an obstacle to providing dental treatment. Determination of degree of malocclusion, identification of consequences of no treatment, establishing goals and outcomes of treatment should be a must. 


\section{REFERENCES}

1. J R Korenberg, X N Chen, R Schipper, Z Sun,R Gonsky, S Gerwehr, N Carpenter, C Daumer, P Dignan, and C Disteche " Down syndrome phenotypes: the consequences of chromosomal imbalance"', PNAS May1994; 11: 4997-5001.

2. David R. Musich, DMD, MS Schaumburg "Orthodontic Intervention \& Patients with Down syndrome, The Role of Inclusion, Technology \& Leadership", Angle Orthodontics J, 2006; 1-2.

3. Sindoor S. Desai, BDS " Down syndrome: A Review of the Literature" Oral Surgery, Oral Medicine, Oral Pathology, Oral Radiology, and Endodontics September 1997; 84(3): 279-85.

4. Elizabeth S. Pilcher, DMD Department of Prosthodontics College of Dental Medicine Medical University of South Carolina " Your Child's Dental Health " (c) Down syndrome News, November 1996; 20; 9: 114.

5. Ash MM and Ramfjord SP Occlusion, 3rd edn. Philadelphia: W.B. Saunders Co 1982.

6. Proffit WR and Fields HW. Contemporary Orthodontics. Chicago: Mosby Year Book, 2000: 1-15

7. Corrucini RS. An epidemiological transition in dental occlusion in world population. Am J Orthod Dentofacial Ortho, 1984 ; 86: 419-426.

8. McDonald F and Ireland AJ. Diagnosis of the Orthodontic Patient. New York: Oxford University Press 1998.

9. Houston WJB, Stephens CD and Tulley WJ. A Textbook of Orthodontics, Great Britain: Wright, $1992: 1-13$.

10. Bjork A, Krebs AA and Solow B. A method for epidemiological registration of malocclusion. Ac Odontol Scand, $1964 ; 22: 27-41$.

11. Angle EH. Classification of malocclusion. Dental Cosmos, 1899; 4: 248-264

12. Draker HL Handicapping labial lingual deviations. A proposed index for public health purposes. Am J Orthod Dentofacial Orthop, 1960 ; 46: 295-305.

13. Brook PH and Shaw WC. The development of an index of orthodontic treatment priority. Eur J Ortho, 1989; $11: 309-320$.

14. Richmond S, Shaw WC, O'Brien KD, Buchanan BI, Jones R, Stephens CD, Roberts CT and Andrews M. The development of the PAR index (Peer Assessment Rating): reliability and validity. Eur J Ortho, 1989; 14: 125-139.

15. Mars M, Plint DA, Houston WJ, Bergland O and Semb G The Goslon Yardstick. A new system of assessing dental arch relationships in children with cleft lip and palate. Cleft Palate Craniofac J, 1987; 24(4): 314-322.

16. BS Phulari. Orthodontics Principals and Practice. 1st edn. 2011:3-4.

17. Right diagnosis.com (homepage on the Internet) US: US Census Bureau population Estimates, US Census Bureau International Data Base; 2004 (Update: 1 February, 2012) available from: http://www.rightdiagnosis.com/d/down_syndrome/stats-country.htm.

18. Kummer A. W. Cleft Palate and Craniofacial Anomalies: Effects on Speech and Resonance. 2nd edition. The United States of America: Thomson Delmar learning, 2008.

19. Folakemi A Oredugba and Yinka Akindayomi. Oral health status and treatment needs of children and young adults attending a day centre for individuals with special health care needs. BMC Oral Health. 2008 October 22. doi: 10.1186/1472-6831-8-30.

20. Senka MentroviE, Martina MikmiE, Jadranka ctefanac-PapiE, Jasmina StipetiE Prevalence of Malocclusion in Patients with Down's Syndrome. Acta Stomatol Croat, Vol. 36, br. 2, 2002

21. Reema Saied Al-Shawaf, BDS, A Radiographic Study of the Dental and Orofacial Manifestations of Down's syndrome in Saudi Patients. 2010.

22. Abu Affan,A.H,P.J wisth and O.E.Boe, Malocclussion in 12 years old Sudanese children . Odontostomal Trop, 1990.13(3): P 87-93.

23. Oliveira AC, Paiva SM, Campos MR, Czeresnia D. Factors associated with malocclusions in children and adolescents with Down syndrome. Am J Orthod Dentofacial Orthop. 2008 Apr;133(4):489.

24. Basma K. AI Sakarna, BDS, M Dent Sci, JDB Enas Othman, BDS, JDB. Denofacial changes and oral health status in individuals with Down syndrome in Jordan. Pakistan Oral \& Dental Journal Vol 30, No. 1, (June 2010).

25. Onyeaso CO.Orthodontic. treatment need of mentally handicapped children in Ibadan, Nigeria, according to the dental aesthetic index. J Dent Child (Chic). 2003 May-Aug; 70 no. 2: 159-63.

26. Dinesh RB, Arnitha HM, Munshi AK. Malocclusion and orthodontic treatment need of handicapped individuals in South Canara, India. Int Dent J. 2003 Feb; 53 no. 1: 13-8. 